Goldschmidt 2021 Abstract

https://doi.org/10.7185/gold2021.7505 contaminant source influences the oral bioaccessibility of PTEs in Belfast topsoil.

\section{Influences of Contaminant Source over Oral Bioaccessibility of Potentially Toxic Elements in Belfast Topsoils}

\author{
TATIANA COCERVA ${ }^{1}$, SIOBHAN COX ${ }^{1}$, SABRINA \\ CIPULLO $^{2}$, RORY DOHERTY ${ }^{1}$, ULRICH OFTERDINGER ${ }^{1}$, \\ MARK CAVE $^{3}$, MANUS CAREY ${ }^{1}$, REBEKKA \\ MCILWAINE $^{4}$ AND FREDERIC COULON $^{5}$ \\ ${ }^{1}$ Queen's University Belfast \\ ${ }^{2}$ Solar Impulse Foundation \\ ${ }^{3}$ British Geological Survey \\ ${ }^{4}$ Belfast City Council \\ ${ }^{5}$ Cranfield University \\ Presenting Author: tcocerva01@qub.ac.uk
}

Potentially Toxic Elements (PTEs) in urban soils often originate from both geogenic and anthropogenic sources. Understanding PTEs mobility, distribution, and geochemical interactions provide the necessary evidence to effectively assess the risks posed to people from exposure to soil contaminants.

Topsoils in Belfast (Northern Ireland) contain elevated concentrations of PTEs ( $\mathrm{Ni}, \mathrm{Cr}, \mathrm{V}, \mathrm{As}, \mathrm{Pb}, \mathrm{Cu}$, and $\mathrm{Zn}$ ) known to be related to historical development zones and underlying geology. In some areas, concentrations in soil exceed the generic assessment criteria (GAC) posing a potential risk to human health. However, most GAC for soils assume that $100 \%$ of the contaminants present in the soils are bioavailable to humans, which often overestimates the risks. Therefore, bioaccessibility testing can be applied to measure the soil contaminant fraction dissolved in digestive tract and available for absorption by the human body.

This study investigates how PTEs bioaccessibility is influenced by the geogenic and anthropogenic sources across the urban area of Belfast. Soil samples overlying different bedrock types, land uses, and development zones were collected from across study area, and oral bioaccessibility testing was undertaken using the Unified BARGE Method. Historical development zones were related to higher PTE bioaccessibility for $\mathrm{Cu}(0.4$ to $68.1 \%), \mathrm{Zn}$ (5 to $78.2 \%)$, As (6.8 to $82.9 \%)$ and $\mathrm{Pb}$ ( 8.8 to $100 \%$ ), while factors linked to geogenic sources were associated with a reduction in oral bioaccessibility fractions for $\mathrm{Cr}(0.5$ to $5.7 \%), \mathrm{V}$ (3.3 to $23.4 \%$ ), and $\mathrm{Ni}$ (1 to $45.7 \%$ ).

Bioaccessibility results were combined with data obtained from a non-specific sequential extraction and chemometric (CISED) analysis to determine whether a relationship exists between the overall concentrations of PTEs and their bioaccessibility. The solid phase distribution results revealed high mobility of PTEs such as $\mathrm{As}, \mathrm{Cu}, \mathrm{Zn}$, and $\mathrm{Pb}$ and their association with easily extracted components during CISED method, such as carbonates, site-specific component and clays. However, $\mathrm{Cr}$, Ni, and $\mathrm{V}$ were predominantly associated with components most difficult to extract during CISED, including intergrown iron oxides with clays, and iron oxides.

Overall, the outcomes of this research indicate that the 